\title{
Association between major depressive disorder and pro-inflammatory cytokines and acute phase proteins among HIV-1 positive patients in Uganda
}

Kenneth Musinguzi ${ }^{1}$, Andrew Obuku ${ }^{1}$, Noeline Nakasujja ${ }^{2}$, Harriet Birabwa ${ }^{3}$, Juliet Nakku ${ }^{3}$, Jonathan Levin ${ }^{4}$ and Eugene Kinyanda ${ }^{1,2,5^{*}}$

\begin{abstract}
Background: Major depressive disorder (MDD) is a common psychiatric complication of HIV/AIDS. While considerable research has been undertaken to understand the psychosocial risk factors of MDD, there is a paucity of data on its biological risk factors including immunological factors. To address this we undertook a study to investigate the association between MDD and pro-inflammatory cytokines and acute phase proteins among persons living with HIV/AIDS (PLWHA) in Uganda. We collected clinical and laboratory data on 201 PLWHA attending two HIV clinics in central and southwestern Uganda. Clinical data included DSM-IV based MDD diagnosis, while laboratory data included the concentrations of IL-6, TNF-a and CRP measured using ELISA. Multiple logistic linear regression analysis was used to determine which proteins were independently significantly associated with MDD controlling for study site, sex, age and highest educational attainment.

Results: The prevalence of MDD was 62/201 (30.8\%). Adjusting for confounders, the odds of MDD increased with increasing levels of IL-6 [each unit increase in IL-6 titres was associated with an aOR $=0.98(95 \% \mathrm{Cl}, 0.97-0.99) ; p<0$. 001]. Participants with low levels of TNF-a were at reduced risk of MDD compared to participants with no TNF-a [those with a TNF-a of $1-<50 \mathrm{pg} / \mathrm{ml}$ titres had an aOR $=0.35(95 \% \mathrm{Cl}, 0.10-1.16)]$, but as the level of TNF-a increased, the risk of MDD increased, and in particular participants with high levels of TNF-a (of 500 or above) were at a significantly increased risk of MDD [e.g. those with a TNF-a of 500- $<1000 \mathrm{pg} / \mathrm{ml}$ titres had an aOR $=3.98(95 \% \mathrm{Cl}, 1$. 29-12.33)] compared to participants with no TNF-a. There was no evidence that MDD was associated with the level of CRP titres [aOR $=0.95(0.78-1.15) ; p=0.60)]$.
\end{abstract}

Conclusion: In this study, the pro-inflammatory proteins IL-6 and TNF-a were significantly associated with MDD, while CRP was not.

Keywords: Major depressive disorder, Pro-inflammatory cytokines, Acute phase proteins, HIV, TNF-a, II-6

\footnotetext{
* Correspondence: eugene.kinyanda@mrcuganda.org

${ }^{1}$ MRC/UVRI, Uganda Research Unit on AIDS, P.O. Box 49, Entebbe, Uganda

${ }^{2}$ Department of Psychiatry, Makerere College of Health Sciences, Kampala,

Uganda

Full list of author information is available at the end of the article
} 


\section{Backround}

According to projections by the World Health Organization (WHO), by the year 2030 major depressive disorder (MDD) will result in more years of life lost to disability than any other illness [1]. HIV/AIDS is associated with a heavy burden of MDD with studies reporting rates of between 3 and 54\% [2-8]. MDD in HIV/AIDS, apart from impairing quality of life, is associated with faster HIV diseases progression [9], poor adherence to anti-HIV medication [10], increased risky sexual behaviour [11] and may lead to mortality through its association with suicidal behaviour [2]. While a lot of work has been undertaken to understand the psychological and social risk factors of MDD in HIV/AIDS in the African context, there is paucity of data on its biological risk factors including immunological mechanisms. Understanding the immunological mechanisms underlying MDD in chronic infections such as HIV/AIDS may provide insights that may facilitate the development of new drug targets [12], biomarkers for diagnosis [13] and treatment response [14].

One of the theories that has been postulated to explain the association between MDD and immune activation following an infection like HIV is the '5-hydroxytryptamine' (5-HT) hypothesis of depression [12]. According to this theory, immune activation (following an infection such as HIV/AIDS) releases pro-inflammatory cytokines such as interferon gamma (IFN $\gamma$ ), interleukin 6 (IL-6), and tumor necrosis factor alpha (TNF- $\alpha$ ) which induce secretion of indoleamine 2, 3-dioxygenase (IDO). IDO activation leads to lower plasma tryptophan (a precursor of the neurotransmitter serotonin whose depletion has been implicated in MDD) and an increased synthesis of detrimental tryptophan catabolites (TRYCATs) such as kynurenine, kynurenic acid, xanthurenic acid, and quinolinic acid which have been shown to be depressogenic [12]. Immune activation including increased production of proinflammatory cytokines and acute phase proteins has repeatedly been described in MDD. Meta-analyses by both Howren and others(2009) and Dowlati and colleagues (2010) have reported an association between MDD and increased circulating peripheral concentrations of the proteins: acute phase proteins (CRP), IL-6, and interleukin 1 (IL-1) receptor antagonist and TNF $\alpha$ $[15,16]$. We therefore hypothesised that MDD in HIV/ AIDS will be associated with elevated levels of proinflammatory cytokines and acute phase proteins. To investigate this in the HIV situation of Uganda, we undertook a study among ART naïve HIV positive adults at two HIV clinics in central and south-western Uganda.

\section{Methods}

\section{Study design}

This was a cross-sectional study nested within a bigger study that was investigating the association between
MDD and psychosocial risk factors in HIV [8, 17]. Study participants were ART naïve patients attending two specialised HIV clinics run by the AIDS Support Organisation (TASO) at Entebbe (semi-urban) and Masaka (predominantly rural) [18]. The MRC/UVRI Uganda Research Unit (the host research institution) has established research collaboration with these two study clinics. Out of 1100 participants enrolled for the main study, a random sample of 201 participants was selected using tables of random numbers to provide plasma samples for the immunological sub-study.

\section{Study questionnaire}

A structured standardised questionnaire administered by trained psychiatric nurses was used to collect the sociodemographic and clinical data for the mother study. The following socio-demographic factors that were relevant to the immunological sub-study were collected age, gender, highest educational attainment, religion, employment status, marital status and socio-economic index (SEI) which was constructed from commonly available household items in a typical Ugandan households, with higher scores reflecting higher socio-economic status [19]. Clinical data collected included the CD4 count and an assessment for major depressive disorder (MDD) using the Mini International Neuropsychiatric interview (M.I.N.I. Plus), a structured interview based on the DSM-IV and ICD-10 classifications [20].

\section{Immunological assessment}

Plasma IL-6, TNF- $\alpha$ and CRP concentrations were measured by ELISA. Anti human TNF- $\alpha$ (MAb TNF3/4) and IL-6 antibodies (MAb 13A5) were purchased from MABTECH AB, Sweden whereas the anti human CRP antibody (Part 842676) was purchased from Research \& Diagnostics ( $R$ \&D) systems, USA.

Briefly, 96-well immunolon 2HB micro plates (Thermo Labsystems, USA) were coated with anti human monoclonal antibodies (IL-6 at $0.25 \mu \mathrm{g} / \mathrm{ml}$, TNF- $\alpha$ at $1.5 \mu \mathrm{g} / \mathrm{ml}$ and CRP at $2 \mu \mathrm{g} / \mathrm{ml}$ ) at $100 \mu \mathrm{l}$ per well and incubated over night at $4{ }^{\circ} \mathrm{C}$. The following day, the coated plates were washed three times using $200 \mu \mathrm{l}$ of PBS containing $0.05 \%$ Tween, pH 7.4 (Sigma-Aldrich, USA) and blocked for $1 \mathrm{~h}$ (at room temperature) with $200 \mu \mathrm{l}$ of PBS and $0.05 \%$ Tween 20 (Sigma-Aldrich, USA) containing 0.1\% MACS BSA buffer (Miltenyi Biotec, Germany). The stored plasma samples were thawed on the bench, diluted using the provided ELISA Diluent (1,2 for IL- 6 and TNF- $\alpha$ )/Reagent Diluent (at 1:6400 for CRP) and $100 \mu$ ladded in duplicates and then incubated at room temperature for $2 \mathrm{~h}$. The plates were washed four times with $200 \mu \mathrm{l}$ of PBS containing $0.05 \%$ Tween 20 and $100 \mu \mathrm{l}$ of anti human IL-6 (MAb 39C3), TNF- $\alpha$ (MAb TNF5) or CRP (Part 842677) biotinylated detection antibodies $(0.5 \mu \mathrm{g} / \mathrm{ml}$ for both IL-6 
and TNF- $\alpha$ then $125 \mathrm{ng} / \mathrm{ml}$ for CRP) were added and incubated at room temperature ( $1 \mathrm{~h}$ for both TNF- $\alpha$ and IL- 6 and $2 \mathrm{~h}$ for CRP). After the plates were washed as stated above, $100 \mu \mathrm{l}$ of Streptavidin-HRP was added (diluted in incubation buffer at 1:2000 for both IL-6 and TNF- $\alpha$, and 1:200 for CRP) and incubated (1 h for both IL- 6 and TNF- $\alpha$, and $20 \mathrm{~min}$ for CRP) at room temperature. After further washes as stated above, $100 \mu \mathrm{l}$ of TMB-substrate (KPL, USA for the IL- 6 and TNF- $\alpha$ and R \& D systems, USA for CRP) was added for colour development. The assay reaction was stopped by adding $1 \mathrm{M}$ sulphuric acid (100 $\mu \mathrm{l}$ to the IL-6 and TNF- $\alpha$ and $50 \mu \mathrm{l}$ to the CRP) and the optical densities were measured immediately using a microplate reader (Biotek uQuant, USA) set to $450 \mathrm{~nm}$. Any samples whose C.V were greater than $15 \%$ were repeated.

\section{Data analysis}

Using STATA (version 12.0), the median concentrations of TNF-a, IL- 6 and CRP were computed and compared between participants with MDD and those without MDD. Multiple logistic linear regression analysis was used to determine which inflammatory protein was independently significantly associated with MDD after controlling for study site, sex, age and highest educational attainment. A $p$-value of $\leq 0.05$ was considered statistically significant. Additionally, using the software Prism Version $6.0 \mathrm{~h}$, graphs were generated from this data.

\section{Ethical considerations}

The study obtained ethical approval from the Uganda Virus Research Institute's Science and Ethics Committee and the Uganda National Council of Science and Technology. Only study clinic attendees who were not impaired in anyway and had full cognitive insight were asked to participate in this study. Study participants who agreed to part in this study provided written consent after being provided with adequate information about the study. Respondents found to have significant psychiatric problems were referred to the psychiatric departments at Entebbe district hospital (at the semiurban site) and Masaka regional referral hospital (rural site) for further assessment and management.

\section{Results}

\section{Socio-demographic and clinical characteristics and their association with MDD}

Table 1 shows the socio-demographic and clinical factors of the 201 participants in this study broken down by whether or not they had MDD. Overall MDD prevalence was $62(30.8 \%)$. More than half of the participants came from TASO Masaka and participants from Masaka were more likely to have MDD than participants from TASO Entebbe (41.1\% vs. $18.1 \%)$. Almost $80 \%$ of participants were female and female participants had a slightly higher prevalence of MDD than male participants $(32.5 \%$ vs. $24.4 \%)$. About one third of participants were aged 18-29 years, one third were aged 30-39 and one third were aged 40 or over. There was no clear trend of MDD with age. Almost two thirds of participants had primary level as the highest level of education, while almost one quarter had secondary or higher education; those with secondary or higher education had a lower prevalence of MDD than those with primary or no education. Half of the participants were currently married; the prevalence of MDD was highest among the widowed and lowest among the currently married. Over half of the participants were Catholic; there was no clear pattern of MDD varying between different religions. Almost 37\% of participants worked as traders, artisans or in the transport sector, with a further $30 \%$ involved in farming or fishing. MDD was highest among participants who were unemployed or retired. The prevalence of MDD decreased with increasing socio-economic status. About one quarter of participants had a baseline CD4 count of below 350 cells $/ \mu \mathrm{l}$ (and thus qualified for ART under the then prevailing ART guidelines) with a further quarter having CD4 counts between 350 and 499 cells $/ \mu$ l. There was no clear pattern of MDD increasing or decreasing with CD4 count.

\section{Inflammatory proteins by MDD status}

Figure 1 shows the bivariate associations between the inflammatory proteins and MDD. The IL- 6 concentration was significantly higher among MDD participants compared to those without MDD $(p<0.0001$; Median $22.4 \mathrm{pg} / \mathrm{ml}$ for MDD participants $n=62$ and $5.762 \mathrm{pg} / \mathrm{ml}$ for participants with no MDD $n=139$; Fig. 1B). There was a trend suggesting higher TNF- $\alpha$ concentrations among MDD participants compared to those without MDD $(p=0.0765$; median $22.98 \mathrm{pg} / \mathrm{ml}$ for MDD participants $\mathrm{n}=62$ and $12.41 \mathrm{pg} / \mathrm{ml}$ for participants with no MDD $n=139$; Fig. 1C). There was no trend between CRP and MDD $(p=0.7499$; Fig. IA).

\section{Multivariate analysis of the association between immunological proteins and MDD}

According to Table 2, participants in Masaka were more likely to have MDD than those in Entebbe. There was no evidence that gender, age or education level influenced MDD. Adjusting for the confounders there was no evidence that MDD was associated with the level of CRP. IL- 6 and TNF- $\alpha$ were associated with MDD (Table 2) in that the odds of MDD increased with increasing IL-6, but in a non-linear fashion. Having any TNF- $\alpha$ decreases the odds of MDD, but as the level of 
Table 1 Depression status of patients by Socio-demographic factors and CD4 counts

\begin{tabular}{|c|c|c|c|c|}
\hline Factor & Level & No MDD $(n=139)$ & Has MDD $(n=62)$ & Total $(n=201)$ \\
\hline Overall & & 139 (69.2\%) & $62(30.8 \%)$ & 201 \\
\hline \multirow[t]{2}{*}{ Study Site } & Entebbe & $73(82.0 \%)$ & $16(18.0 \%)$ & $89(44.3 \%)$ \\
\hline & Masaka & $66(58.9 \%)$ & $46(41.1 \%)$ & $112(55.7 \%)$ \\
\hline \multirow[t]{2}{*}{ Sex } & Male & $31(75.6 \%)$ & $10(24.4 \%)$ & 41 (20.4\%) \\
\hline & Female & $108(67.5 \%)$ & $52(32.5 \%)$ & $160(79.6 \%)$ \\
\hline \multirow[t]{5}{*}{ Age (years) } & $18-29$ & $51(76.1 \%)$ & $16(23.9 \%)$ & $67(33.3 \%)$ \\
\hline & $30-34$ & $27(69.2 \%)$ & $12(30.8 \%)$ & $39(19.4 \%)$ \\
\hline & $35-39$ & $16(61.5 \%)$ & $10(38.5 \%)$ & $26(12.9 \%)$ \\
\hline & $40-49$ & $27(56.2 \%)$ & $21(43.8 \%)$ & 48 (23.9\%) \\
\hline & $50+$ & $18(85.7 \%)$ & $3(14.3 \%)$ & $21(10.4 \%)$ \\
\hline \multirow[t]{3}{*}{ Education Level } & None & $15(62.5 \%)$ & $9(37.5 \%)$ & $24(11.9 \%)$ \\
\hline & Primary & $86(66.7 \%)$ & $43(33.3 \%)$ & $129(64.2 \%)$ \\
\hline & Secondary or higher & $38(79.2 \%)$ & $10(20.8 \%)$ & 48 (23.9\%) \\
\hline \multirow[t]{5}{*}{ Marital Status } & Current married & $73(72.3 \%)$ & $28(27.7 \%)$ & $101(50.2 \%)$ \\
\hline & Widowed & $18(60.0 \%)$ & $12(40.0 \%)$ & $30(14.9 \%)$ \\
\hline & Separated/Divorced & $36(66.7 \%)$ & $18(33.3 \%)$ & $54(26.9 \%)$ \\
\hline & Single & $10(71.4 \%)$ & $4(28.6 \%)$ & $14(7.0 \%)$ \\
\hline & Missing & $2(100 \%)$ & 0 & $2(1.0 \%)$ \\
\hline \multirow[t]{5}{*}{ Religion } & Catholic & $80(66.7 \%)$ & $40(33.3 \%)$ & $120(59.7 \%)$ \\
\hline & Protestant & $23(74.2 \%)$ & $8(25.8 \%)$ & $31(15.4 \%)$ \\
\hline & Muslim & $24(72.7 \%)$ & $9(27.3 \%)$ & $33(16.4 \%)$ \\
\hline & Seventh Day Adventist & $3(75.0 \%)$ & $1(25.0 \%)$ & $4(2.0 \%)$ \\
\hline & Born Again & $9(69.2 \%)$ & $4(30.8 \%)$ & $13(6.5 \%)$ \\
\hline \multirow[t]{5}{*}{ Employment Status } & Farmer/Fisherman & $44(71.0 \%)$ & $18(29.0 \%)$ & $62(30.8 \%)$ \\
\hline & Professional/Clerical & $9(90.0 \%)$ & $1(10.0 \%)$ & $10(5.0 \%)$ \\
\hline & Trader/Artisan/Transport & $51(68.9 \%)$ & $23(31.1 \%)$ & $74(36.8 \%)$ \\
\hline & Unemployed/Retired & $12(52.2 \%)$ & $11(47.8 \%)$ & $23(11.4 \%)$ \\
\hline & Student/Other & $23(71.9 \%)$ & $9(28.1 \%)$ & $32(15.9 \%)$ \\
\hline \multirow[t]{4}{*}{ Socio-economic status index } & $<=12$ & $26(57.8 \%)$ & $19(42.2 \%)$ & $45(22.4 \%)$ \\
\hline & $13-15$ & $52(68.4 \%)$ & $24(31.6 \%)$ & $76(37.8 \%)$ \\
\hline & $16-19$ & $44(73.3 \%)$ & $16(26.7 \%)$ & $60(29.8 \%)$ \\
\hline & $20+$ & 17 (85.0\%) & $3(15.0 \%)$ & $20(10.0 \%)$ \\
\hline \multirow[t]{5}{*}{ CD4 count (grouped) } & $<250$ cells $/ \mu \mathrm{l}$ & $20(76.9 \%)$ & $6(23.1 \%)$ & $26(12.9 \%)$ \\
\hline & $250-349$ & $15(60.0 \%)$ & $10(40.0 \%)$ & $25(12.4 \%)$ \\
\hline & $350-499$ & $43(76.8 \%)$ & $13(23.2 \%)$ & $56(27.9 \%)$ \\
\hline & $500-749$ & $45(68.2 \%)$ & $21(31.8 \%)$ & $66(32.8 \%)$ \\
\hline & $>=750$ cells $/ \mu \mathrm{l}$ & $16(57.1 \%)$ & $12(42.9 \%)$ & $28(13.9 \%)$ \\
\hline
\end{tabular}

TNF- $\alpha$ increases, the odds of MDD increase. Participants with low levels of TNF- $\alpha$ showed reduced risk of MDD compared to participants with no TNF- $\alpha$, but as the level of TNF- $\alpha$ increase, the risk of MDD increases, and in particular participants with high levels of TNF- $\alpha$ (of 500 or above) were at a significantly increased risk of MDD. In summary, the odds of MDD increased with increasing levels of IL-6; participants with low levels of TNF- $\alpha$ were at reduced risk of MDD compared to participants with no TNF$\alpha$, but as the level of TNF- $\alpha$ increased, the risk of MDD increased, and in particular participants with high levels of TNF- $\alpha$ (of 500 or above) were at a significantly increased risk of MDD. 


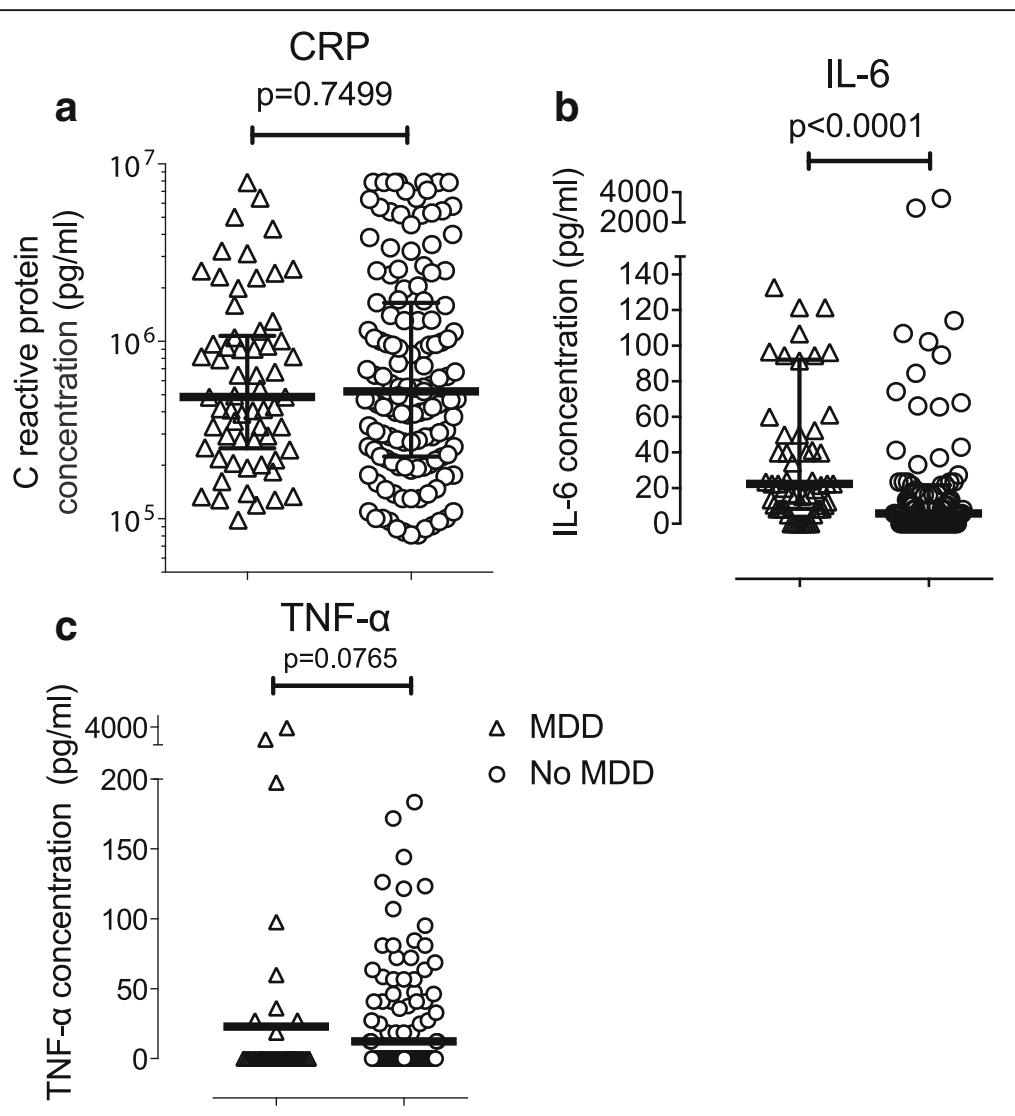

Fig. 1 Association of CRP (a), IL-6 (b) and TNF-a (c) with major depressive disorder. Each symbol (triangle or circle) represents CRP, IL-6 or TNF-a concentration in the plasma of each participant. Within each data cluster for MDD or No MDD, the middle line is the median and outer lines are the interquartile range

Table 2 Multiple logistic linear regression model for Major depressive disorder

\begin{tabular}{lllc}
\hline Factor & Level & aOR $(95 \%$ Cl) & LR P-value \\
\hline Study Site & Entebbe & 1 (Reference Level) & 0.003 \\
& Masaka & $3.30(1.46 ; 7.45)$ & \\
Sex & Male & 1 (Reference Level) & 0.48 \\
& Female & $1.40(0.54 ; 3.66)$ & \\
Age (years) & Per one year increase & $0.981(0.944 ; 1.020)$ & 0.32 \\
Education Level & None & 1 (Reference Level) & 0.88 \\
& Primary & $1.16(0.38 ; 3.51)$ & \\
& Secondary & $0.93(0.25 ; 3.41)$ & \\
CRP & Per 1 million increase & $0.95(0.78 ; 1.15)$ & 0.60 \\
100/(IL-6+1) & Per unit increase & $0.979(0.969 ; 0.989)$ & $<0.001$ \\
TNF-a & 0 & $1($ Reference Level) & $<0.001$ \\
& $1-<50$ & $0.35(0.10 ; 1.16)$ & \\
& $50-<500$ & $0.31(0.10 ; 0.94)$ & \\
& $500-<1000$ & $3.98(1.29 ; 12.33)$ & \\
& $1000+$ & $7.24(1.65 ; 31.82)$ & \\
\hline
\end{tabular}

\section{Discussion}

This is one of the first studies from sub-Saharan Africa that has investigated the association between proinflammatory cytokines and acute phase proteins and major depressive disorder (MDD) in HIV. In this study, IL-6 was significantly independently positively associated with MDD. An increase in the risk of MDD with increasing levels of IL-6 mRNA has been reported in previous studies undertaken in the developed world both among persons living with HIV (PLWHA) [21] and in other medical conditions such as cancer [22], cardiovascular disease, osteoporosis [23] and among the elderly [24]. In this study, TNF- $\alpha$ was significantly independently positively associated with MDD. In a systematic review that involved 13 studies, Dowlati and colleagues (2010) reported a statistically significant positive association between TNF- $\alpha$ levels and MDD [16]. In this study, while the overall positive association between TNF- $\alpha$ levels and MDD was true at TNF- $\alpha$ concentrations above $500 \mathrm{pg} / \mathrm{ml}$, the relationship between TNF- $\alpha$ and MDD was the reverse at TNF- $\alpha$ concentrations below $500 \mathrm{pg} / \mathrm{ml}$. This non-linear association between TNF- $\alpha$ and MDD has not previously been reported. 
In this study, there was no association between $\mathrm{C}$ reactive protein (CRP) and MDD. Previous studies have reported conflicting results on the association between CRP and MDD, while some studies have observed a positive association between CRP and depressive symptoms [15, 25-27], others have not [28]. The relationship between CRP and MDD appears to be further complicated by sex and race. Morris and colleagues (2011) in the USA observed a positive association between CRP and MDD among female Caucasians but not among male Caucasians and not among African Americans of either sex [26]. Therefore the lack of association between CRP and MDD observed in this study could be due to race differences. There is however need for more African studies to confirm this finding.

\section{Conclusion}

In conclusion, as hypothesized in this study, MDD was generally associated with elevated pro-inflammatory proteins. These results suggest a possible aetiological role for pro-inflammatory proteins in MDD. But since this study was cross-sectional in design, we could not determine the direction of causality between the pro-inflammatory proteins and MDD. Secondly, since we assumed that HIV and MDD are each independently associated with inflammation, an HIV negative control group would have been required in order to investigate the independent effect of MDD on inflammation. To resolve these issues will in future require the use of a longitudinal study design in order to delineate the actual direction of causality and the inclusion of an HIV negative control group. However contrary to the set hypothesis, MDD was not associated with acute phase proteins. As discussed above this may have been due to differences in race.

\begin{abstract}
Abbreviations
AIDS: Acquired immunodeficiency syndrome; ART: Antiretroviral therapy; CRP: C-reactive protein; DSM-IV: Diagnostic and Statistical Manual for Mental Disorders, 4th edition; EDCTP: European and developing countries' clinical trials partnership; ELISA: Enzyme linked immunosorbent assay; HIV: Human immunodeficiency virus; ICD: International Classification of Diseases; IDO: Indoleamine 2,3-dioxygenase; IgG: Immunoglobulin Gamma; IL: Interleukin; M.I.N.I: Mini International Neuropsychiatric interview; mAb: Monoclonal antibody; MDD: Major depressive disorder; mRNA: Messenger ribonucleic acid; PLWHA: Persons living with HIV/AIDS; TASO: The AIDS Support Organization; TNF-a: Tumour necrosis factor alpha; TRYCATs: Tryptophan catabolites; WHO: World Health Organization
\end{abstract}

\section{Acknowledgements}

We wish to thank the staff of TASO Entebbe and TASO Masaka who helped with recruitment and examination of study participants and as well as collecting samples. We are also grateful to the study participants for agreeing to take part in the study.

\section{Funding}

This study was funded through a Senior Fellowship to Eugene Kinyanda by The European \& Developing Countries Clinical Trials Partnership (EDCTP) under Grant No. TA.10.40200.011.

\section{Availability of data and materials}

The datasets used and/or analysed during the current study are available from the corresponding author on reasonable request.

\section{Authors' contributions}

EK designed the study, KM and $\mathrm{AO}$ performed the immunology experiments, NN, HB and JN collected data for the MINI Plus, $\mathrm{J}$ analysed the data. All authors contributed to the write up of the manuscript and read and approved the final manuscript.

\section{Ethics approval and consent to participate}

The study obtained ethical approval from the Uganda Virus Research Institute's Science and Ethics Committee and the Uganda National Council of Science and Technology. Study participants were invited to consent after being provided with adequate information about the study. Respondents found to have significant psychiatric problems were referred to the psychiatric departments at Entebbe district hospital (at the semi-urban site) and Masaka regional referral hospital (rural site) for further assessment and management.

\section{Consent for publication}

Not applicable.

\section{Competing interests}

Eugene Kinyanda obtained funding from EDCTP to undertake this study. The authors Kenneth Musinguzi, Andrew Ekii Obuku, Noeline Nakasujja, Harriet Birabwa, Juliet Nakku, and Jonathan Levin have no competing interests to declare.

\section{Publisher's Note}

Springer Nature remains neutral with regard to jurisdictional claims in published maps and institutional affiliations.

\section{Author details}

${ }^{1}$ MRC/UVRI, Uganda Research Unit on AIDS, P.O. Box 49, Entebbe, Uganda. ${ }^{2}$ Department of Psychiatry, Makerere College of Health Sciences, Kampala, Uganda. ${ }^{3}$ Butabika National Psychiatric Referral Hospital, Kampala, Uganda. ${ }^{4}$ School of Public Health, University of the Witwatersrand, Johannesburg, South Africa. ${ }^{5}$ Senior Wellcome Trust Fellowship, London, UK.

Received: 5 July 2017 Accepted: 19 December 2017

Published online: 03 January 2018

\section{References}

1. WHO. Projected burden of disease in 2030, In: The Global Burden of Diseases 2004, Update, p. 48-52. http://www.who.int/healthinfo/global_ burden_disease/GBD_report_2004update_full.pdf?ua=1. Accessed: 30th September 2017.

2. Kinyanda E, Hoskins S, Nakku J, Nawaz S, Patel V. Prevalence and risk factors of major depressive disorder in HIV/AIDS as seen in semi-urban Entebbe district, Uganda. BMC Psychiatry. 2011; https://doi.org/10.1186/1471-244X-11-205.

3. Lyketsos CG, Hoover DR, Guccione M, Dew MA, Wesch J, Bing EG, et al. Depressive symptoms over the course of HIV infection before AIDS. Soc Psychiatry Psychiatr Epidemiol. 1996;31(3-4):212-9.

4. Perry S, Jacobsberg LB, Fishman B, Frances A, Bobo J, Jacobsberg BK. Psychiatric diagnosis before serological testing for the human immunodeficiency virus. Am J Psychiatry. 1990;147(1):89-93.

5. Gorman JM, Kertzner R, Todak G, Goetz RR, Williams JB, Rabkin J, et al. Multidisciplinary baseline assessment of homosexual men with and without human immunodeficiency virus infection. I. Overview of study design. Arch Gen Psychiatry. 1991;48(2):120-3.

6. Seth R, Granville-Grossman K, Goldmeier D, Lynch S. Psychiatric illnesses in patients with HIV infection and AIDS referred to the liaison psychiatrist. Br J Psychiatry. 1991;159:347-50.

7. Hoover DR, Saah A, Bacellar H, Murphy R, Visscher B, Metz S, et al. The progression of untreated HIV-1 infection prior to AIDS. Am J Public Health. 1992;82(11):1538-41.

8. Kinyanda E, Nakasujja N, Levin J, Birabwa H, Mpango R, Grosskurth $\mathrm{H}$, et al. Major depressive disorder and suicidality in early HIV infection and its association with risk factors and negative outcomes as seen in semi-urban and rural Uganda. J Affect Disord. 2017;212:117-27.

9. Collins PY, Holman AR, Freeman MC, Patel V. What is the relevance of mental health to HIV/AIDS care and treatment programs in developing countries? A systematic review. AIDS. 2006;20(12):1571-82. 
10. Leserman J. Role of depression, stress, and trauma in HIV disease progression. Psychosom Med. 2008;70(5):539-45.

11. Springer SA, Dushaj A, Azar MM. The impact of DSM-IV mental disorders on adherence to combination antiretroviral therapy among adult persons living with HIV/AIDS: a systematic review. AIDS Behav. 2012;16(8):2119-43.

12. Maes M, Leonard BE, Myint AM, Kubera M, Verkerk R. The new '5-HT hypothesis of depression: cell-mediated immune activation induces indoleamine 2,3-dioxygenase, which leads to lower plasma tryptophan and an increased synthesis of detrimental tryptophan catabolites (TRYCATs), both of which contribute to the onset of depression. Prog NeuroPsychopharmacol Biol Psychiatry. 2011;35(3):702-21.

13. Almeida SM. Cognitive impairment and major depressive disorder in HIV infection and cerebrospinal fluid biomarkers. Arq Neuropsiquiatr. 2013;71(9B):689-92.

14. Lanquillon S, Krieg JC, Bening-Abu-Shach U, Vedder H. Cytokine production and treatment response in major depressive disorder. Neuropsychopharmacology. 2000;22(4):370-9.

15. Howren MB, Lamkin DM, Suls J. Associations of depression with C-reactive protein, IL-1, and IL-6: a meta-analysis. Psychosom Med. 2009;71(2):171-86.

16. Dowlati Y, Herrmann N, Swardfager W, Liu H, Sham L, Reim EK, et al. A meta-analysis of cytokines in major depression. Biol Psychiatry. 2010;67(5):446-57.

17. Kinyanda E, Weiss HA, Levin J, Nakasujja N, Birabwa H, Nakku J, et al. Incidence and persistence of major depressive disorder among people living with HIV in Uganda. AIDS Behav. 2017;21 (6):1641-54.

18. The AIDS Support Organisation. In Wikipedia. 2017. https://en.wikipedia.org/ wiki/The_AIDS_Support_Organization. Accessed on 30 ${ }^{\text {th }}$ September 2017.

19. Kinyanda E, Waswa L, Baisley K, Maher D. Prevalence of severe mental distress and its correlates in a population-based study in rural south-west Uganda. BMC Psychiatry. 2011;11:97.

20. Sheehan DV, Lecrubier Y, Sheehan KH, Amorim P, Janavs J, Weiller E, et al. The mini-international neuropsychiatric interview (M.IN.I.): the development and validation of a structured diagnostic psychiatric interview for DSM-IV and ICD-10. J Clin Psychiatry. 1998;59(Suppl 20):22-33.

21. Warriner EM, Rourke SB, Rourke BP, Rubenstein S, Millikin C, Buchanan $L$, et al. Immune activation and neuropsychiatric symptoms in HIV infection. J Neuropsychiatry Clin Neurosci. 2010;22(3):321-8.

22. Musselman DL, Miller AH, Porter MR, Manatunga A, Gao F, Penna S, et al. Higher than normal plasma interleukin-6 concentrations in cancer patients with depression: preliminary findings. Am J Psychiatry. 2001;158(8):1252-7.

23. Alesci S, Martinez PE, Kelkar S, llias I, Ronsaville DS, Listwak SJ, et al. Major depression is associated with significant diurnal elevations in plasma interleukin-6 levels, a shift of its circadian rhythm, and loss of physiological complexity in its secretion: clinical implications. J Clin Endocrinol Metab. 2005;90(5):2522-30.

24. Tiemeier H, Hofman A, van Tuijl HR, Kiliaan AJ, Meijer J, Breteler MM Inflammatory proteins and depression in the elderly. Epidemiology. 2003;14(1):103-7.

25. Song BM, Lee JM, Choi LW, Youm Y, Chu SH, Park YR, et al. Association between $\mathrm{C}$ reactive protein level and depressive symptoms in an elderly Korean population: Korean social life, health and aging project. BMJ Open. 2015:5(2):e006429.

26. Morris AA, Zhao L, Ahmed Y, Stoyanova N, De Staercke C, Hooper WC, et al. Association between depression and inflammation-differences by race and sex: the META-health study. Psychosom Med. 2011;73(6):462-8.

27. Miller GE, Stetler CA, Carney RM, Freedland KE, Banks WA. Clinical depression and inflammatory risk markers for coronary heart disease. Am J Cardiol. 2002;90(12):1279-83.

28. Pan A, Ye X, Franco OH, Li H, Yu Z, Wang J, et al. The association of depressive symptoms with inflammatory factors and adipokines in middleaged and older Chinese. PLoS One. 2008;3(1):e1392.

\section{Submit your next manuscript to BioMed Central and we will help you at every step:}

- We accept pre-submission inquiries

- Our selector tool helps you to find the most relevant journal

- We provide round the clock customer support

- Convenient online submission

- Thorough peer review

- Inclusion in PubMed and all major indexing services

- Maximum visibility for your research

Submit your manuscript at www.biomedcentral.com/submit
Biomed Central 